ISOLATION IN ISOLATION HOSPI'TAJS. Br H. \&. CORBIN, B.Sc, D.P.H.,

Medical Officer of Health, and Medical Superintendent of the Isolation Hospital, Stockport, late Medical Superintendent of the London Fever Hospital.

I $N$ a paper on "The Influence of Hospital Isolation on Scarlet Fever," by Dr. Killick Millard, read before the Incorporated Society of Medical Officers of Health, February, 1901, Dr. Millard concludes :-

1. That the hospital isolation of scarlet fever appears to have failed materially to reduce the prevalence of the disease.

2. That the hospital isolation of scarlet fever appears to have failed materially to reduce the fatality of the disease.

3. That the fatality of the disease has fallen most on those large towns which have not practised hospital isolation.

He has come to these conclusions by an uppeal to statistics.

In a later paper read before the same Society, Dr. J. R. Kaye shewed the futility of comparing small groups of towns with reference to the isolating policy, without having regard to all the factors involved, such as position, social character of the people, housing accommodation, thoroughness of notification, and compulsory school attendance.

We know so little of what have been called "epidemic influences" that we have no means of determining what would have been the prevalence, or the mortality of the infections fevers without isolation hospitals. It is in the very nature of every disease which is caused by a specitic organism, to undergo in the course of years more or less sudden variation, both in incidence and in virulence, and it is probable that the increased incidence from infectious diseases, giving rise to epidernic peaks and plateaux is an indication of an increase in the infectivity of the invading micro-organism due to conditions of enviromment which are farourable to it, or which in some way reduce the resistance of those which it attacks, or, perhaps, a combination of these. A crest in a wave of infectivity may occur at the same time with a trough in a wave of resistance in a community, the result being an epidemic: peak. As to what are the influences at work which determine and bring about these changes, we must, unfortunately, confess a large amount of ignorance.

In the discussion on Dr. Kaye's paper, Dr.
Malet, of Wolverhampton, mentioned the results of some valuable inquiries he had made in cases of scarlet fever, as to the number of infectable children in houses from which the patients were removed to hospital (as a rule overcrowded houses), and in houses where isolation was possible, and the patients were not removed to hospital. During eight years he had cases from 1,758 houses in which 4,864 infectable children (not having had scarlet fever) remained. Cases were treated in 228 houses, with 468 children remaining infectable. Of the children left at home after hospital removal, 4.8 per cent. contracted scarlet fever. Of the children in the houses isolated at home 28.2 per cent., or more than six times as inany contracted the disease.

These facts are quoted as shewing the unquestionable value of removing cases to hospital, and though it is not my intention in this paper to discuss in detail the question as to whether isolation hospitals have diminished epidemic prevalence or lowered mortality, it seems to me, from the definition of the word infectious, to be an axiom, that the removal of an infectious patient to a hospital will minimise the possibility of the disease spreading; and that isolation hospitals, notwithstanding adverse criticism, constitute not the least of many important factors in the organization. to promote public health.

In the year 1862 , " certain non-professional sanitary reformers proclaimed to the world that all cases of infectious disease ought to be distributed through the wards of a general hospital, and denounced the London Fever Hospital (then the only fever hospital in Lomdon), as a crime against humanity." The objections urged were two :-

1. That the concentration of the poison increases the mortality among the patients themselves.

2. That the concentration of the poison increases the danger to the attendants.

"The validity of these objections may be tested by comparing the results of the London Ferer Hospital during the year 1862 with those of six of the principal general hospitals of the metropolis.

"During the first six months of 1862, 1,107 cases of true typhus were under treatment in the London Fever Hospital, of which 232 died, or the mortality was 20.95 per cent. In the sarne period, 343 cases of typhus were under treatment in six of the general hospitals in London (St. Bartholomew's, Guy's, St. Thomas's, 
Middlesex, St. Mary's, and the German Hospital) ; of these 343 cases, 80 died, or 23.32 per cent. The $1,080(1,107-27)$ cases admitted to the fever hospital communicated the disease to 27 persons, of whom 8 died. In other words, only one person took the fever for every 40 admitted, and only 1 died for every 135 . But the 272 cases admitted into the six general hospitals, communicated the disease to 71 persons, of whom 21 died, or 1 person caught the fever for every $3 \cdot 1$ cases admitted, and 1 . was lost for every $12 \cdot 9$ cases admitted. It appears from this that the objections raised against the fever hospital, however plausible in theory, are not justified by facts, and that a given number of typhus patients can be treated on the plan of isolation, with equal advantage to themselves, and with far less danger to the attendants and other patients, than in the wards of a general hospital."--(Extract from Report of the London Fever Hospital, 1862).

From the opening of the London Fever Hospital in 1802, up to 1863 , no separation between the patients suffering from different diseases admitted into the hospital was affected, but on account of the frequency with which the patients contracted other diseases than those for which they were admitted, it was deemed necessary to adopt the plan of isolating in separate wards the typhus and scarlet fever patients from the other patients, and from one another. The results were most satisfactory.

Since then much has been effected throughout the country towards increasing and rendering efficient the policy of the isolation of infectious diseases, and it is with the object of advocating greater efficiency in isolation that I have given the title of "Isolation in Isolation Hospitals" to this paper, and in order to promote discussion, and to learn the views of others.

Until within the last few years, very little accommodation was provided for complete isolation of cases admitted to the fever hospitals. Inadequate isolation accommodation not infrequently necessitates the exposure to infection of cases not suffering from the disease for which they are sent to hospital, and also increases the passibility of the introduction of other infectious diseases into the wards.

Cases requiring complete isolation are:-

1. Dorbtful cases.

2. Cases in which two infectious diseases co-exist.
3. Cases of one disease which have been exposed to another infection before admission to hospital.

4. Cases suffering from infections complications.

5. Verminous cases.

6. Other diseases not infectious.

With regard to the separation of cases suffering from infectious complications, much discussion has taken place. The so-called isolation of the infectious diseases, as carried on at the present time, really consists of aggregation of cases suffering from similar diseases, the extent of this aggregation being determined by the size of the wards and the number of patients treated within them at a given time; in other words, upon the cubic space per patient.

Overcrowding of patients in a ward unquestionably increases the incidence of complication, such as otorrhoea, adenitis, and rhinorrhoa, and to what other cause can this be attributed than that these conditions are infectious? To allow that they are more frequent in overcrowded and ill-ventilated wards is to admit that they are infectious, and I am inclined to the view that even 1,000 cubic feet of air-space in a well-ventilated room, completely separated from other patients, is of more value than an average of 2,000 cubic feet of air space, which is common to a large number of patients suffering from an infectious disease.

Dr. Cameron, in his report on "Return Cases," after discussing various views on the matter, says: "It follows from the evidence, which I have adduced elsewhere, that the limitation of 'return cases' lies in the direction of preventing the spread of complications in hospital."

A rough classification of acute and convalescents into different wards is now adopted in many hospitals with a view to securing greater freedom from infection and to diminish the possibility of return cases. This method is older than is generally supposed, for in the report on the hospitals of the United Kingdom, published by the medical officer of the Privy Council in 1864, it is written of the London Fever Hospital: "It seems to us, too, that the plan on which the convalescent wards are conducted, in virtue of which convalescents are removed from the infected atmosphere of the acute wards and 'sorted,' so as to guard them as much as possible from all risk of contagion, is worthy of special notice." 
In a recent lecture on the "Treatment of Infectious Diseases," Dr. E. IV. Croodall, speaking of diminishing "jeturn cases," says: "The employment of separate wards for severe and mild cases does not appear to be of any avail towards this end."

With regard to the influence of aggregation of cases in a warl on the incidence of infections complications, I find that in the case of 794 patients arbnitted into the general scarlet fever warls at the Tondon Fever Hospital, 38.3 suffered from infectious complications or forty per cent., while in the case of 66 patients treated throughout in single rooms 12 suffered from such complications or $18^{\circ} 2$ per cent. I have included in the term infectious complications, otorrhoea, rhinorrhora, aclenitis, secondary tonsilitis, and nephritis.

Now as to what extent isolation should be carried out, and what should be the proportion of isolation rooms per cent. of patients. The medical superintendents of the Metropolitan Asylums Board, in commenting on Dr. Cameron's report on return cases cane to the conclusion that 20 per cent. of the total beds should be set aside, $10 \mathrm{for}$ mixed infectious and 10 for dombtful cases, and "other diseases."

Dr. J. J. Clark, of Walthanstow, in a personal communication, expressed the opinion that every case of diphtheria should be treated throughout in cubicles, and that 40 per cent. of the scarlet ferer beds should be in cubicles, the patient being treated in these until throat, gland, and ear symptoms aro absent.

Jt is a far ay from the present system of aggregation to that of complete isolation of so large a proportion of patients, or still more, to the ideal systern in which every patient is kept apart from the time of entry to that of exit from hospital.

Let us now consider what methors have been adopted in this direction, and how far up to the present they have been successful.

Perhaps the most well-known instance of a hospital in which every case is, at least for a time, isolated in a separate room, is the Pastenr Hospital, in Paris. In the centre of each pavilion there are twenty-fou chambres d'isolement, or boxes, arranged in two storeys of twelve each. The cells are arranged six on either side of a central corridor. Each of. these opens into the central corridor, and on to an ontside balcony. The cells are separated into pairs by brick walls, while the division of each pair, and also the whole front facing the corridor, consists of a brick wall up to abont 3 feet from the floor, and glass from this to the ceiling. Complete absence of air commmication is thus brought about when the doon is closed, and the materials used in the construction of the cribicles are such that they can readily be washed and disinferted. Each cubicle is $11 \times 9$ feet, and has a cubic: content of about 1,500 cubic feet. Hot and cold water is supplierl to each combicle.

Dr. Ionis Martin, the resident physician, describes in Le Bulletin Medical, 19th Mareh, 1904, a copy of which he kindly gave me, the régime of asepsis, which is carried out by the doctors and murses in order to prevent communication of liseases, and which, apart from the wearing of a separate overall for attendance on each patient, consists of the ordinary principles of asepsis. Mr. Louis Martin states that in about two and a half years, 2,000 patients were treated, comprising 443 of diphtheria, 524 of smallpox, 55 of chicken pox, 126 of measles, 92 of scarlet fever, and 163 of erysipelas; the remainder being doubtful or non-infectious cases.

Every case admitted is raccinated when the hospital contains small-pox cases, and every infant under three years receives a prophylactic injection of antitoxin when there are diphtheria cases in the hospital.

Dr. Martin states that only six cases of cross-infection occurred-four of small-pox and two of erysipelas-or 03 per cent. of the 2,000 cases.

Such figures clearly slow the practicability of such an arrangenent, for the treatment of: infectious diseases, when administered in an efficient manner.

The nearest approach to this that we have in England is at the Isolation Hospital of the Walthamstow Urban District Council, where there is a twelve-bed pavilion, consisting of glass cubicles, designed by Mr. G. W. Holmes, A.M.I.C.E., the council's engineer, in consultation with Dr. J. J. Clarke, medical officer of healt t. A central nurses' duty room divides the pavilion into two sets of six cubicles, each with 144 square feet of floor space and 2,000 cubic feet of content. The dividing partitions are of concrete to a height of 2 fect, the remaindler being of glass, which reaches to the ceiling. Each cubicle has a window and a door. which opens to the onter air. A verandah overhangs the doorways on either side of the building. Ventilation is effected by the windows, and 

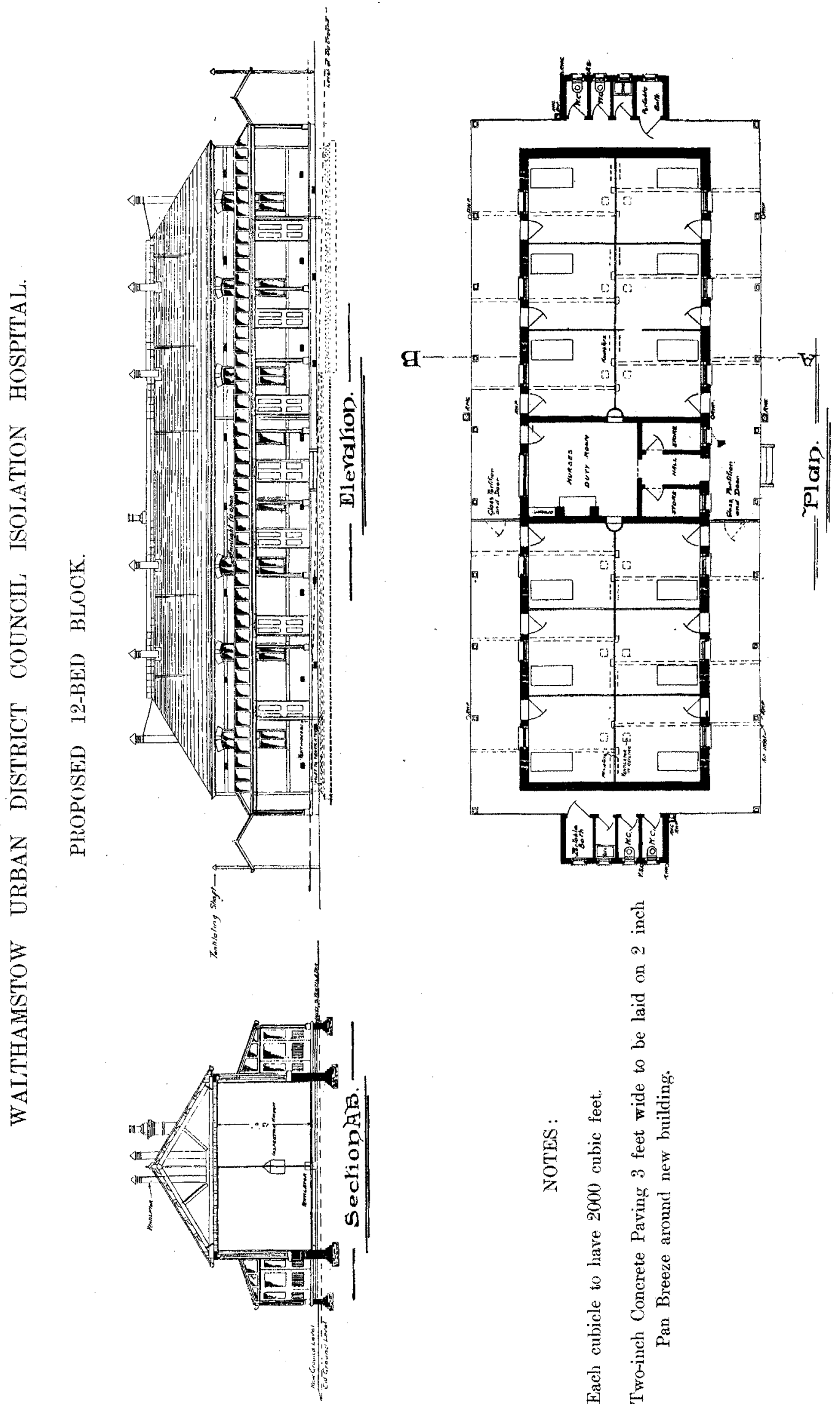
by anl air duct which comes up through the floor and conveys air from the opposite side of the building. Each cubicle is heated by a radiator. Between every two cubicles, outside the building, is a lavatory basin with hot and cold water fitted. The chief disadvantage of this arrangement appears to be the exposure of the nurses to inclement weather, as they have to go outsicle from the duty room in order to enter a cubicle, and to wash their hands outside before passing from one cubicle to another. Mr. Holmes has been kind enough to send me plans of this pavilion, which I am able to show you, and I am indebted to Dr. Clarke for some details as to the results obtained. He finds that isolation of different diseases in adjacent cubicles is ample and adequate. Diphtheria, scarlet fever, measles and whooping cough have been treated side by side in the parilion, and no secondary infection has arisen. Moreover, he finds that if patients get bad throat symptoms in the general ward, removal for a few days into a cubicle at once effects an inrprovement without medicinal treatment. The nurse's toilet consists of putting on a cloak on entry to each cubicle and thoroughly washing the hands. From the observation windows of the nurse's duty room, all twelve patients can be seen at once, and at night the electric light may: be turned on in each cubicle from the duty room.

A pavilion constructed on the cubicle system would be a great economy to small local authorities, as it would no longer necessitate two blocks, one for scarlet, and one for diphtheria. There would, moreover, be an economy in the nutsing, and if one disease was epidenicic, all the beds could be used; while if separate special blocks exist for two diseases one of these is frequently nearly empty, while the other is overcrowded.

Dr. Foord Caiger has kindly supplied me with some particulars as to the conversion of two large wards into cubicles at the SouthWestern Hospital of the Metropolitan Asylums Board, in order to supplement the existing isolation.

In these cubicles only partial isolation is effected, as the partitions reach only 7 feet above floor level, and fall considerably short of the ceiling. Dwarf doors about 3 feet high are provided, opening in the central corridor. These are arranged so that the door of one cubicle is not opposite to that of another, and while preventing a child from getting out of the abicle, allows free circulation of air anong the cubicles.

Dr. Caiger states, in a small memorandum referring to these cubicles, "It is believed that for certain cases sufficient protection is furnished by the relative isolation afforded by cubicles, provided scrupulous care is exercised by the attendants, both medical and nursing, who are entrusted with their adninistration. The principle underlying the system is, of course, "aseptic" in its conception."

For the present, the cubicles will be exchusively utilized for temporary isolation of doubtful and anomalous cases, and for certain recognised attacks, which are believed to be unattended with a high degree of infectivity. I look forward with interest to Dr. Caiger's results; they will be specially interesting as an indication of how far one can go with only partial isolation of certain of the infectious diseases.

Mr. Keith Young, F.R.I.B.A., has kindly furnished me with a copy of sketch plans of a proposed new ward block at the London Fever Hospital. The designs are for a twostorey block for 36 patients, each storey consisting of a ten-bed ward on one side, and a group of seven isolation cubicles on the other, separated by a ward kitchen and staircase. Each ward, as well as each series of cubicles, is provided with a sanitary annexe.

As these are sketch plans, and necessarily incomplete, I will not describe them in more detail ; but such an arrangement, while providing ward accommodation for patients suffering from a common disease, affords also excellent accommodation for the complete isolation of either distinct diseases or of patients which it is deemed advisable should be removed from the ward. Such a block would, I believe, materially add to the efficiency and facility of administration of a hospital, in which isolation accommodation is too limited, or would serve excellently as the entire hospital accommodation for a small authority, who wish to provide small general wards for scarlet fever: and diphtheria, as well as isolation for doubiful and other cases. For while available for any disease which is at the time prevalent, the presence of the cubicles adapts the block for admission into hospital of every asse of whatsoever infection that it is thought clesirable to isolate.

In this paper I have attempted to bring an important subject before you. While it is universally agreed that adequate isolation is 


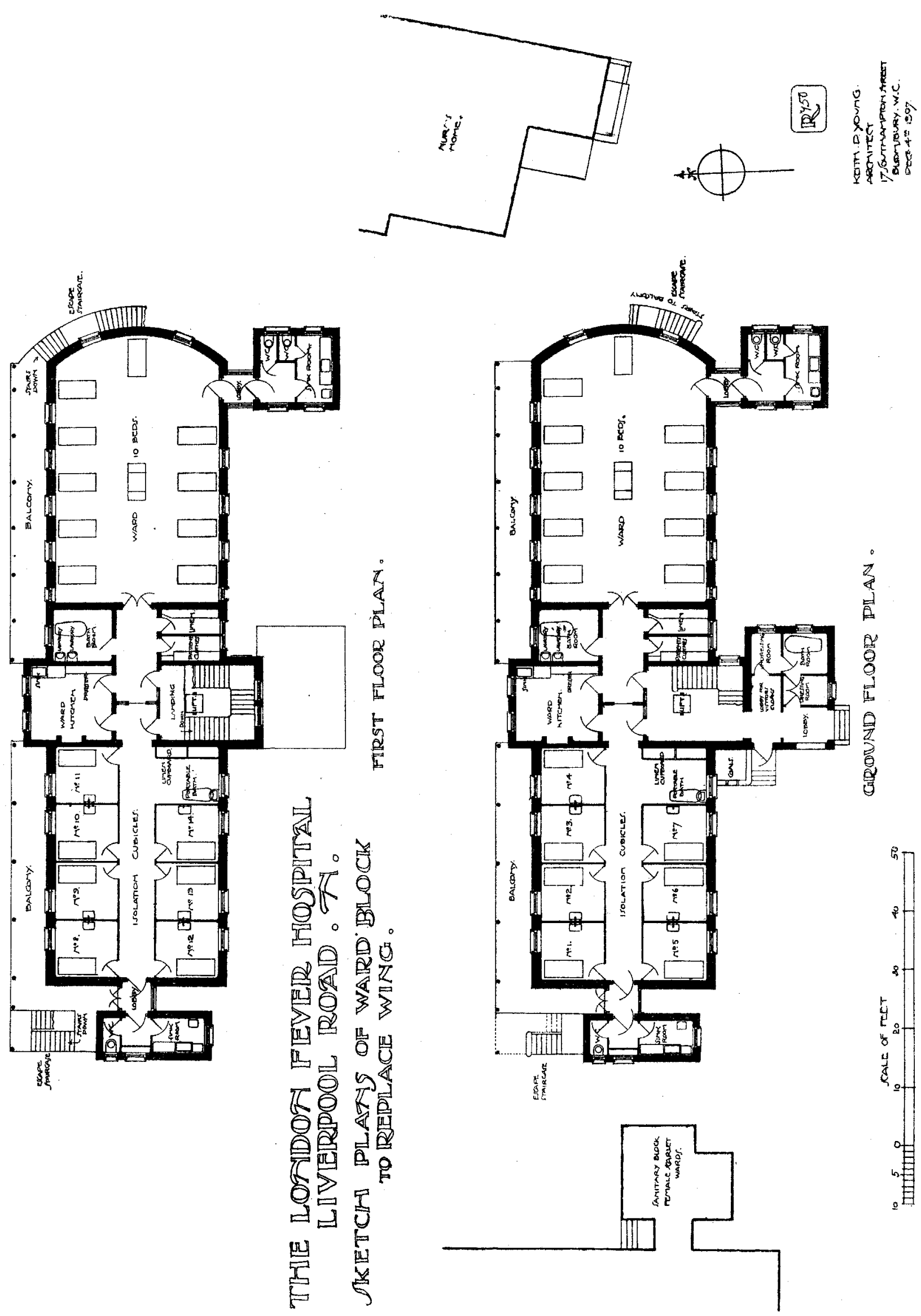


necessary for doubtful cases, dual infections, intercurrent infections, "other diseases," and such like, it is with the insufficient data so far available, a debated point, and up to this time experimental, whether aggregation of cases suffering from one disease is responsible for increased infectivity or prolonged infectivity, and also whether complications, such as adenitis and otorrhoea, are conmoner in ward cases than in cases isolated throughout; and, moreover, if, by a system of more complete isolation, either partial or total, it is possible to limit or abolish the mmch-discussed return cases, or even diminish the incidence of the disease apart from these.

These are questions of minch interest and importance, and though cognizant of my inability to deal adequately with the subject, I have dealt with it with the idea of learning the views of those who have had greater experience, and are more able to judge of these matters than myself.

Overpressure in the Sohools of France (Ia question du surmenage scolaire).-Dr. Albert Mathien (Internat. Mag. of Seh. Hygiene, IV. Band 1 Heft. Feb. 1908) writes strongly on this subject. He says that until but a year ago the children in the écoles maternelles were herded together under most undesirable conditions; there were no playgrounds and no. spontaneous activity encouraged or even allowed; while subjects designed for children of from ten to twelve years of age were prematurely begun. The écoles maternelles correspond with our infants 'departments and are attended by children from the age of two to six; over a unillion children below the official lower age limit attend these schools.] In the elementary schools for children from i to 13 years of age, the hours correspond with those in England, from eight to eleven in the morning and from one to four in the afternoon; but, in addition, much homework is given. He gives the example of a girl of 12, coming home from school at four, starting home lessons at five, going to bed at ten; rising at five and doing home lessons again until school time at eight. The result of this, says Dr. Mathien, is wholesale depreciation of health; amongst other things, neurosthenia and corresponding nervous disorders are rife, while dyspepsia and even dilatation of the stomach may be traced to the same cause. The health of the children is greatly improved during the holidays, but the improvement disappears soon on resuming school. Fatigue is a normal phenomenon, the manifestations of which are important warnings; danger commences when this warning is unheeded or not obeyed. Dr. Mathien refers to the resthesiometric method as very valuable and offering a means of classifying children, so that undue tasks shall not be demanded from those showing little resistance to fatigue.

\section{THE SCHOOL DENTAL CLINICS OF GERMANY.}

B) (. ELW.IRJ WALLIS M.R.C.S., L.R.C.P., L.D.S.

Assistant 1)ental Surgeon, King's College Hospital, Dental Surgeon, Victoria Hospital for Children, Chelsea, and London County Council School, Feltham, etc.

D IRING the last ten years many series of careful observations have been made with a view to finding out the amount of dental lisease existing among the elementary school children of this country, and all observers agree that the amount of decay is enormous, that the ignorance of the community on the subject of the teeth may almost be described as abysmal, and worst of all that, speaking of the country as a whole, little or nothing worthy of the name is being done either as regards the prevention or treatment of dental caries, the commonest disease to which civilized Europeans are subject.

Let us now turn to that home of educational progress, Germany, and what do we find.

Thanks to the untiring efforts of Professor Jessen of Strasburg, somewhere between twenty-two and twenty-nine cities in that country have either in existence or in process of formation school dental surgeries, or "SchuleZahn-Kliniks," to deal with the teeth of their elementary school children.

Strasburg, being the pioneer city, it will be of interest to deal with the way in which Professor Jessen succeeded in impressing upon the municipal authorities the seriousness of the dental situation in the schools, and the steps to be taken to deal with the matter.

Perhaps one ought to mention here that the population of Strasburg is given as 150,000 , that is to say, it is about the same size as Sundertand, and its elementary school population is given as 19,134 children.

In 1895 Professor Jessen, in the face of great opposition, obtained permission to examine the teeth of the school children of Strasburg, and after examining some 10,000, his statistics showed that but 4.3 per cent. had healthy dentition - a proportion which, though bad enough, is not nearly so bad as was shown at the Michael Faraday School in Walworth, where only 1.63 per cent. were found to have healthy sets of teeth when examined by the writer in 1906 .

For some time after this, Professor Jessen had in existence, at his own expense, a school dental clinic, at which he was able to treat a certain number of children; but it was not milil 1902 that the municipal authorities went 